\title{
13 Using school-based early warning systems as a social and behavioral approach for HIV prevention among adolescent girls
}

\author{
A case study from Uganda
}

\author{
Julie DeSoto, Asha Belsan, Robert Wamala, \\ Victor Ochaya, Rita Laura Lulua, Gloria Ekpo, \\ Dennis Cherian and Shelby Benson
}

\section{Introduction}

A growing body of literature discusses social and behavioral approaches to HIV prevention. In a recent literature review of adolescent-focused HIV prevention research by Pettifor et al., (2018), the authors noted the need for combining HIV prevention strategies addressing individual, dyadic (peer/partner/parent), community (e.g. school environment), and societal-level risk and protective factors. In a systematic review of programs for HIV prevention among youth in sub-Saharan Africa, Harrison et al., (2010) concluded there should be emphasis on social risk factors for HIV, including gender, poverty, and alcohol, adding that future programs should work to change social norms and target structural factors contributing to HIV infection among adolescents. In 2008, Coates et al., called on the behavioral science community to better inform promising cognitive-behavioral, persuasive communications, and peer education approaches with theoretical frameworks. More recently, Govender et al., (2018) reviewed key challenges for mitigating HIV risk through sexual contact among young people in Eastern and Southern Africa (ESA), the region with the highest HIV burden. Overall, researchers and practitioners recommend that interventions focused on adolescents and young people should be developed using theoretical frameworks, contain multiple strategies, and comprehensively engage different levels of the ecosystem (schools, communities, individuals, families).

This chapter seeks to respond to these findings by outlining a schoolbased social and behavioral intervention used in Uganda. An overview of the model and its implementation is discussed, with emphasis on the importance of understanding enabling factors and barriers when adapting 
evidence-based HIV prevention approaches to specific contexts. To evaluate effectiveness of the project, the chapter presents findings from an external longitudinal study comparing intervention and control schools at two different times. These outcomes are further contextualized by standardized monitoring data collected by World Vision ${ }^{1}$ and critical insights gathered from field implementers.

\section{The model: strengthening school-community accountability for girls education}

Previous research has identified attendance, behavior, and course performance (ABC predictors) as powerful indicators of secondary school dropout and completion rates. Evidence suggests that using an early warning system (EWS) to track these indicators is an effective approach for predicting and preventing secondary school dropout in the United States and elsewhere (Bruce et al., 2011; Heppen \& Bowles Therriault, 2008; Neild, Balfanz \& Herzog, 2007). This case study documents how the School-Community Accountability for Girls Education (SAGE) project in Uganda was designed and implemented to deliver a combination (ABC predictors plus EWS) school-based HIV prevention project for adolescent girls (AG). SAGE was a two-year PEPFAR-funded project (October 1, 2016-March 31, 2019). Its main goal was to reduce secondary school dropout and ultimately HIV infection among 38,750 AG aged 13-19 in 151 schools across ten districts of Uganda (Sembabule, Mubende, Oyam, Mukono, Gomba, Bukomansimbi, Lira, Rakai, Mityana, and Gulu). SAGE used an innovative EWS package to shift social norms and practices around girls' education, violence against children, reproductive health, and positive discipline. It provided a package of activities (detailed herein) to help girls stay in school and sought to reduce risks of early marriage, pregnancy, and gender-based violence (GBV) as mitigating factors against HIV acquisition. The SAGE model was developed using Urie Bronfenbrenner's ecological systems theory (Bronfenbrenner, 1979), in which different levels of the socioecological model were addressed during the life of the project (the individual, peers, families and schools at the microsystem, mass media, politics and community in the exosystem, and behavior change at the macrosystem). Figure 13.1 is adapted from Bronfenbrenner's (1979) conceptualization of the ecology of human development.

The different levels of the socioecological model were further contextualized for in-school adolescents in Uganda using Susan Sawyer's Life Course Perspective on adolescent health interventions. In this model, interventions considered that adolescents' health is affected by biological and social role changes accompanying puberty, which are shaped by social determinants affecting the uptake of health-related behaviors (Sawyer et al., 2012). Also used was the USAID Positive Youth Development (PYD) model (Figure 13.2), which organizes interventions around developing adolescents' assets, 


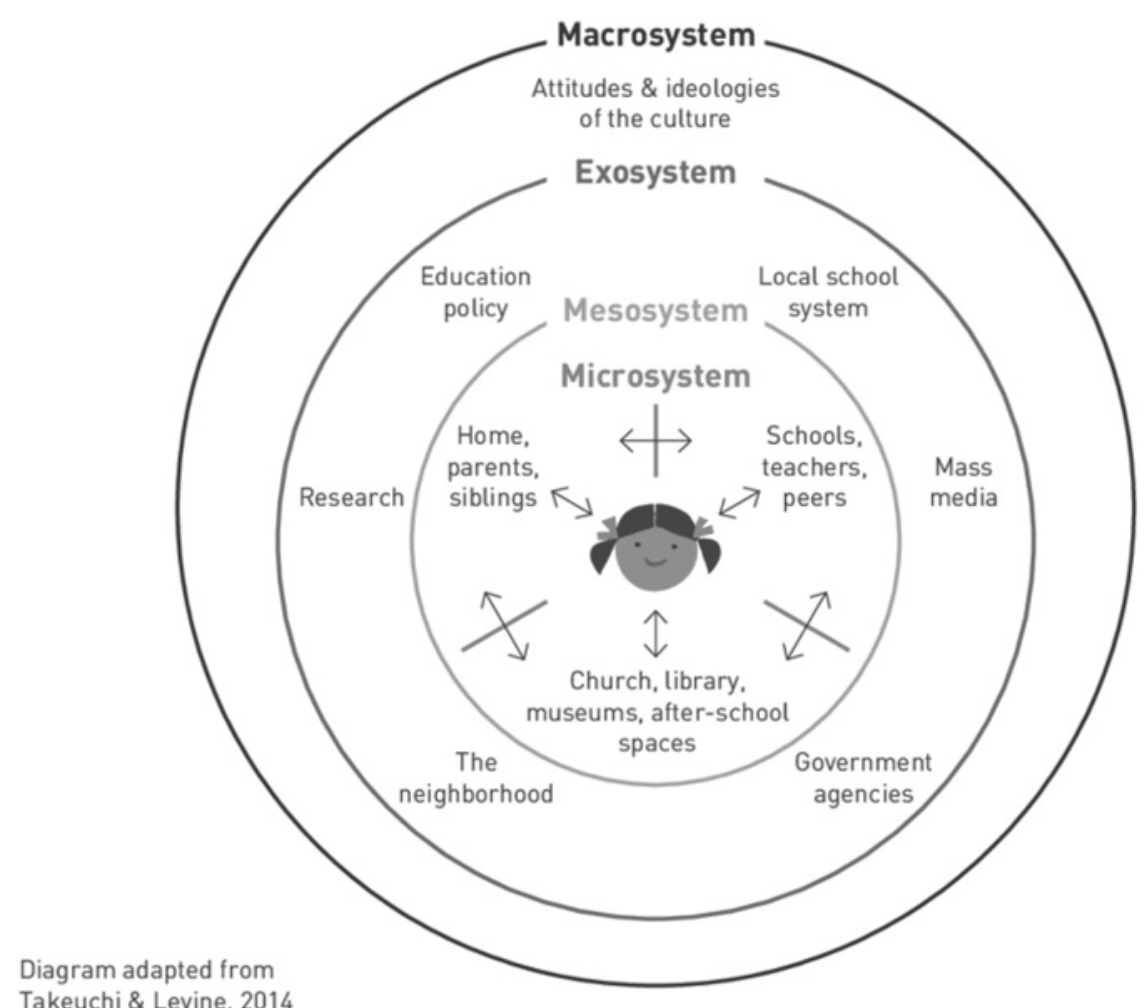

Takeuchi \& Levine, 2014

Figure 13.1 Adaption of Bronfenbrenner's ecological framework for human development

agency, and contribution to the project while supporting an enabling environment (USAID, 2019). Fredric H. Jones's Positive Discipline model was also incorporated, focusing on replacing corporal punishment in the classroom with teachers modeling appropriate behavior and building patterns of cooperation between students (Fred Jones Tools for Teaching, 2019).

\section{SAGE theory of change and implementation framework}

The SAGE theory of change posited that if adolescents at risk of secondary school dropout are detected through the EWS; an environment supporting reduced violence and positive gender norms is improved at home, in school, and in the community; and life skills interventions are accessible to girls, then adolescent girls will have the agency and social support necessary to stay in school, be violence-free, be HIV-free, and thrive. 


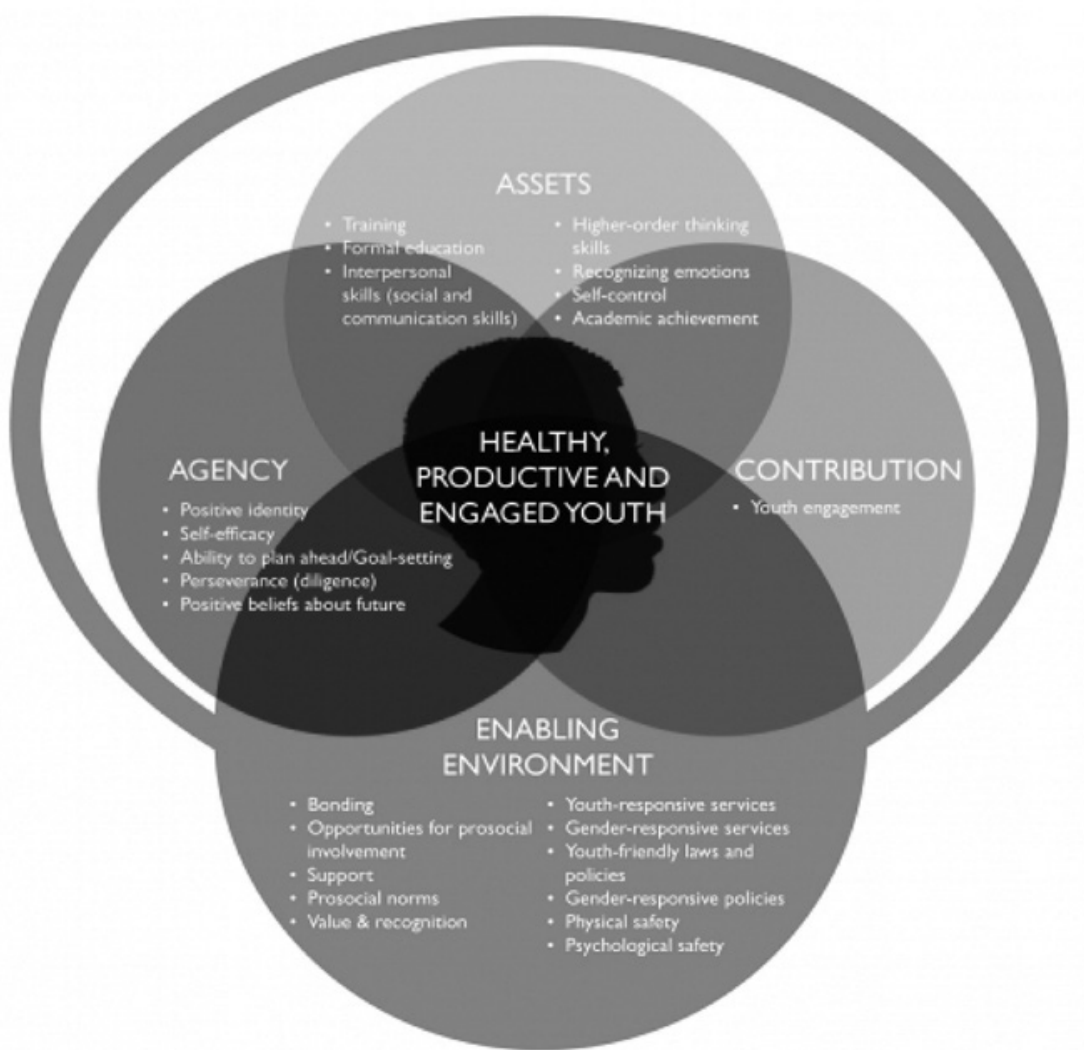

Figure 13.2 USAID Positive Youth Development (PYD) Framework

To respond to the theory of change, the project team developed the EWS package, a school-community monitoring and accountability mechanism helping girls stay in school by addressing all levels of the socioecological model. It involves adolescents, their schools, families, and communities in monitoring students' attendance and taking practical actions to support atrisk students to remain in school. Three key functions of the EWS package are to (1) predict dropout (using the register); (2) prevent dropout (creating an environment where girls are safe and encouraged to learn); and (3) return vulnerable girls to school (through home visits and mentoring) (visit www.worldvision.org/dreams for the full endline report).

The EWS package is an adolescent-led, adult-supported, and evidencebased monitoring and accountability mechanism. Building on guidelines and lessons learned from the five-year (September 27, 2010-September 29, 


\section{Julie DeSoto et al.}

2015) USAID-funded Asia and Middle East Regional School Dropout Prevention Pilot (SDPP) Program in Cambodia, India, Tajikistan, and Timor-Leste, the SAGE EWS package identified critical vulnerabilities (e.g. economic status, death of one or more parents, parental attitudes towards early marriage) and risk factors (attendance patterns, behavior, and course performance) (SDPP Impact Evaluation, Creative Associates International, and Mathematica Policy Research, 2015). These triggered quick actions at the school and community to reduce dropout. World Vision adapted the model to the Uganda context (visit www.worldvision.org/dreams for the adapted manual) and added the adolescent-led peer educator (PE) innovation and action body structure known as the Stay in School Committee (SISC).

Using readily available school data and a project-designed register, schools track three predictors to identify and intervene with girls at risk of dropping out: attendance, behavior, and course performance (ABC). When a reduction in students' performance or attendance or a negative trend in classroom behavior occurs, teachers flag the girls for follow-up and refer them to the SISC (visit www.worldvision.org/dreamsfinal project report for flagging tool and metrics).

SAGE worked to improve student attendance norms by promoting adolescent leadership and community action to reduce dropout. PEs (adolescent girls in each grade chosen by peers by a vote) were trained in GBV reduction, sexual and reproductive health, HIV prevention, and safe school approaches. Once trained, these adult-supported PEs organized training for their peers according to a set plan. Teachers were trained on GBV reduction, positive discipline, and safe school practices. Communities received mass media and community-based dialogue interventions on girls' education, violence, HIV, and school attendance. Faith communities were trained using World Vision's Channels of Hope, a model that engages faith leaders in behavior change through messaging on relevant issues during faith-related gatherings.

The SISC is the main action and accountability body of the EWS package, where most decision-makers are AGs. Each school's SISC consists of 12 to 15 people: six AG PEs and one teacher, older girl, older boy, mother, father, faith leader, head teacher, and school administrator. Once a girl has been flagged, her case is referred to the SISC, which decides on next steps to ensure the girl is supported. The SISC serves as a school-community body tackling identified causes of absenteeism and monitoring and supporting girls to stay in school through the development and implementation of school-community action-oriented work plans. These work plans include home visits to the flagged girls, mobilizing support for school fees, and addressing safety and health issues as applicable.

Each SISC is held accountable for interventions on behalf of the most vulnerable girls. SISCs decide if a girl needs more support in school, what type of support, and if a home visit is needed. The types of support girls 
receive include PEs mentoring the girls one on one or in groups, teachers providing counseling and mentoring, fellow students organizing contributions of items the at-risk girls may lack (sanitary pads, money for meals, etc.), finding sponsors for school fees, training to make reusable sanitary pads, helping with notes and homework, and visiting homes to intervene around GBV, early marriage, or financial issues.

The selection and training of SISC members allows them to be effective advocates for AGs. Home visits are conducted by respected members of the community serving on the SISCs, trained on the issues that surround dropouts in this context. Visits usually consist of a meeting with the girl, her family member, and/or village elders. SISC members discuss the importance of girls' education and social issues. For example, the SISC may explain why early marriage is harmful and advocate for the girl to return to school. Often, a SISC member takes the girl back to the school the same day.

The project supported uptake of the EWS, fostered functionality of SISCs, empowered PEs, engaged communities, and helped ensure vulnerable AGs were linked to comprehensive sexual and reproductive health (SRH), HIV, and GBV services. To engage communities beyond the SISC, World Vision trains faith leaders in GBV issues using the Channels of Hope for Gender curriculum (refer to the final project report at www.worldvision.org/ dreams for an in-depth description of each project activity).

\section{Data (SAGE baseline and endline)}

Previous research indicates school attendance serves as a protective factor against the acquisition of HIV (Stoner et al., 2017). Thus the main objective of this study was to explore the impact of the EWS package in reducing school dropout and increasing school retention among AGs ages 15-19 (as measured by dropouts averted and girls returned to school). The longitudinal study was conducted by Dr. Robert Wamala and his research team based at Makerere University. It gathered data using cross-sectional baseline and endline surveys between 2016 and 2019. The evaluation was meant to demonstrate the extent to which the AG-led EWS helps reduce secondary school dropout among girls. Cross-sectional baseline and endline surveys were conducted for SAGE in 2016 and 2019, respectively. The baseline and endline were conducted in ten intervention districts matched with three comparison (control) districts: Apac, Kayunga and Masaka. In each of these 13 districts, five public secondary schools were randomly selected to serve as supervision areas (SA) for the monitoring of the project performance. Pooled cross-sectional sample surveys conducted at baseline and endline of the project assessed the impact of the project. The quantitative data component of the baseline study was based on a lot quality assurance sampling (LQAS) of AGs and a multi-stage cluster sample of caregivers as described in the subsequent sections. 


\section{Survey sampling design}

School-based surveys of in-school AGs and community-based surveys of caregivers were conducted. The control and intervention districts were socio-demographically similar. The following sections provide a detailed explanation of the design for each of the topical areas.

\section{Stated study assumptions}

1 Percentage of AGs with access to HIV prevention interventions; assumed to be $50 \%$ in the target districts.

2 Retention of AGs in Senior 4 in target schools was 34\% (MoESTS, EMIS, 2013).

3 Percentage of the AGs with comprehensive knowledge about HIV prevention, care, and treatment; assumed to be $50 \%$.

4 Percentage of parents or caregivers actively involved in strategies aimed at reducing HIV acquisition among AGs and in improving retention of their daughters at school; assumed to be $50 \%$.

Of 151 schools where the program was implemented, this study was conducted in five intervention schools and five control schools in each selected district. In total, there were 1310 participants, 950 participants from intervention schools and 360 from control schools. In the intervention districts, an LQAS sample was selected from each of the randomly selected schools. In each school, a list of AGs aged 15-19, organized by class (Senior 1 to Senior 6), was generated by teachers. A systematic random sample of 19 girls was taken from the list. The endline survey was based on a random sample of schools, not necessarily those visited at baseline. Since there are only three districts in the control arm, a LQAS of 24 AGs was sampled from each of the selected schools. Overall, 15 schools and 360 AGs were selected from control districts. This increase in sample size from the control schools was motivated by the fact that LQAS samples across the intervention schools were to be pooled and compared with results from a pooled LQAS sample across control schools. This comparison assured a minimum detectable effect size of $10 \%$ (with $80 \%$ power and $95 \%$ certainty) due to SAGE interventions. Effect size is related to each of the indicators found in the Tables 13.3, 13.4, and 13.5 with consideration of the study's stated assumptions.

This study's data analysis was done using STATA 13.0 at two stages. First, a descriptive summary of participant characteristics was provided through frequency distributions and summary statistics, where applicable. A similar approach was adopted in describing adolescents based on key indicators. Second, differentials in the four key assumptions above between the control and intervention areas were investigated using the Pearson chi-square test. The test was used to assess differences in distribution of participants 
Table 13.1 Description for sampling procedure of adolescent girls per district (baseline and endline)

\begin{tabular}{llllll}
\hline Group & \# schools & $\begin{array}{l}\text { Sample size } \\
\text { per school }\end{array}$ & $\begin{array}{c}\text { \# districts } \\
\text { in baseline }\end{array}$ & $\begin{array}{l}\text { \# AG participating } \\
\text { in }\end{array}$ & $\begin{array}{l}\text { \# AG participating } \\
\text { in endline }\end{array}$ \\
\hline Intervention & 5 & 19 & 10 & 950 & 950 \\
Control & 5 & 24 & 3 & 360 & 360 \\
TOTAL \# AG sample size in control + intervention & 1310 \\
\hline
\end{tabular}

Note: The schools were adopted as the supervision areas in each district.

Table 13.2 Description for sampling procedure of caretakers per district (baseline and endline)

\begin{tabular}{|c|c|c|c|c|c|}
\hline Group & \# villages & $\begin{array}{l}\text { Sample size } \\
\text { per village }\end{array}$ & \# districts & $\begin{array}{l}\text { \# parent/caregiver } \\
\text { participating in } \\
\text { baseline }\end{array}$ & $\begin{array}{l}\text { \# parent/caregiver } \\
\text { participating in } \\
\text { endline }\end{array}$ \\
\hline Intervention & 2 & 21 & 10 & 420 & 420 \\
\hline Control & 4 & 21 & 3 & 252 & 252 \\
\hline \multicolumn{5}{|c|}{ TOTAL \# parent/caregiver sample size in control + intervention } & 672 \\
\hline
\end{tabular}

between the control and treatment group. No significant difference in distribution of participants at baseline was found with regards to age, class, religion and living arrangements. The difference-in-difference (DID) analysis shows differentials in project indicators between baseline and endline. DID analysis was based on linear regressions. For each indicator, difference scores were computed between control and treatment at the baseline and then at endline to enable comparisons. These findings are presented in the section "Key Findings of the Pre and Post Surveys".

\section{Limitations}

One of the key limitations of the study is the lack of adjustment for confounders. The study used a simple DID analysis based on the assumption that there would not have been a diffusion of the intervention to the control group (i.e. no contamination). The limitation of the study is that it did not test for parallel trend assumption. The DID model makes a counterfactual assumption (parallel trend assumption) that a treatment group would grow at the same rate as a control group if there were no intervention. Another limitation was that there were different sets of participants from the baseline to the endline study. Care was taken to ensure distances between intervention and control schools, decreasing the likelihood of DREAMS programming influencing control schools. Although statistically representative, the survey study examined only a small portion of the total 


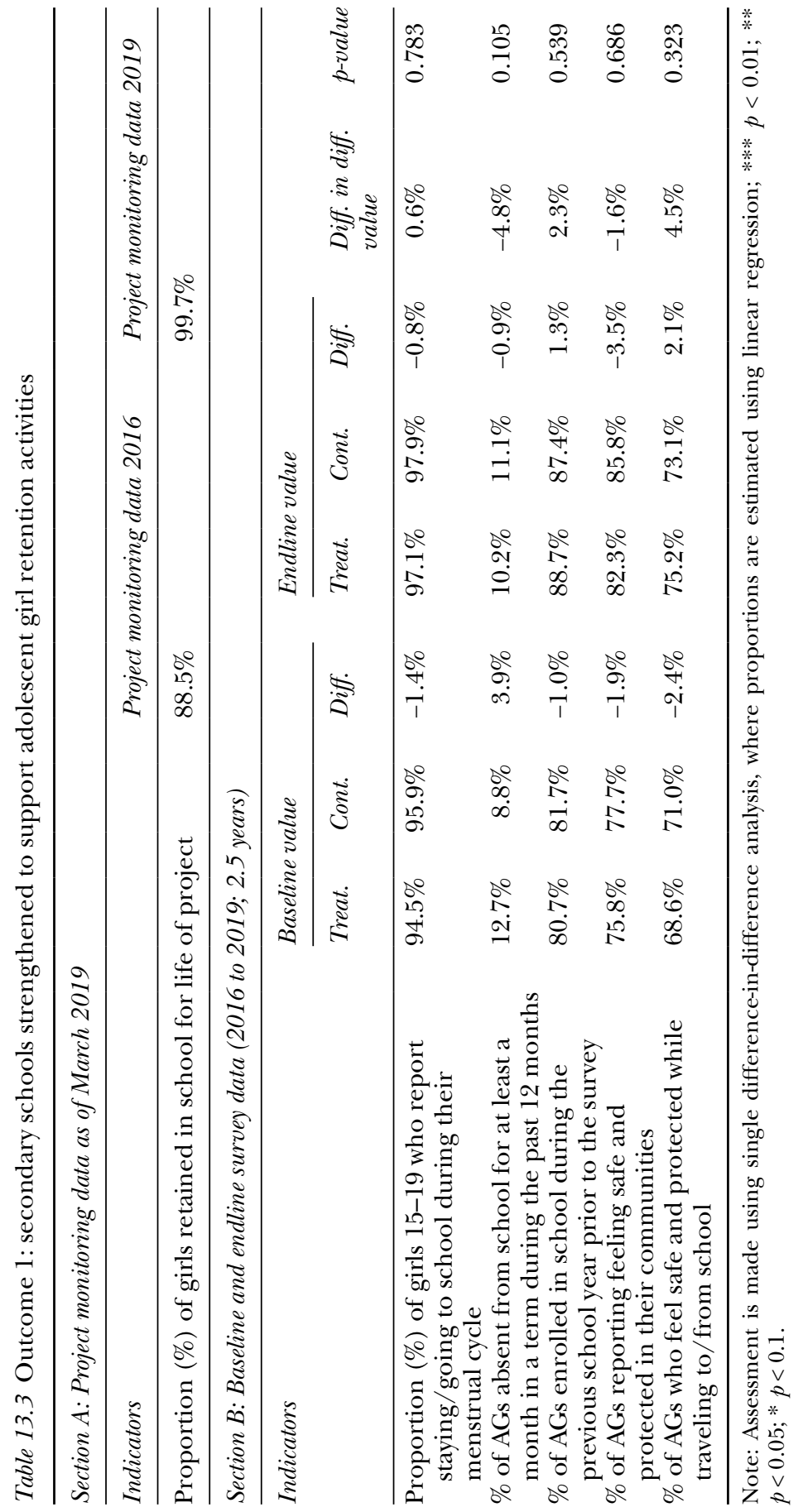


Using school-based early warning systems 289

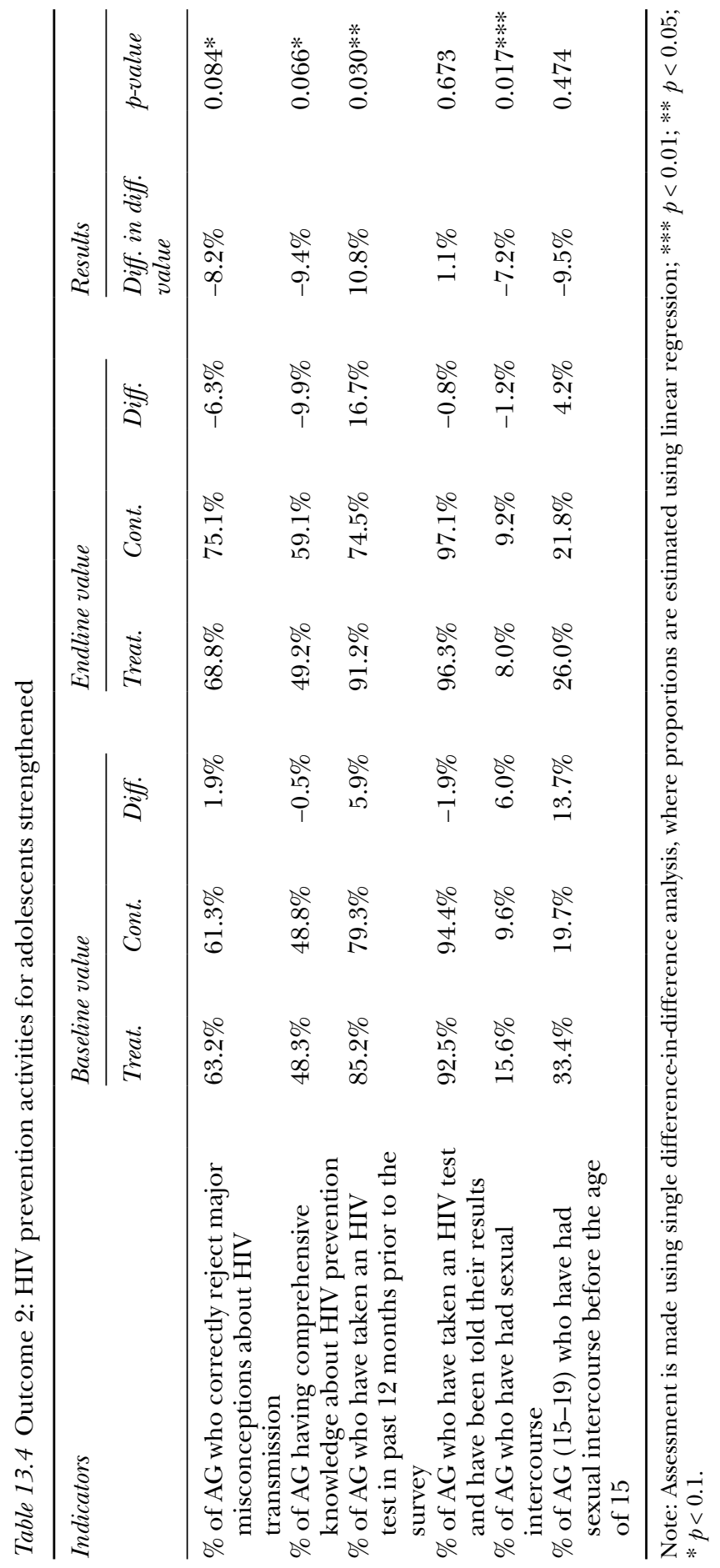




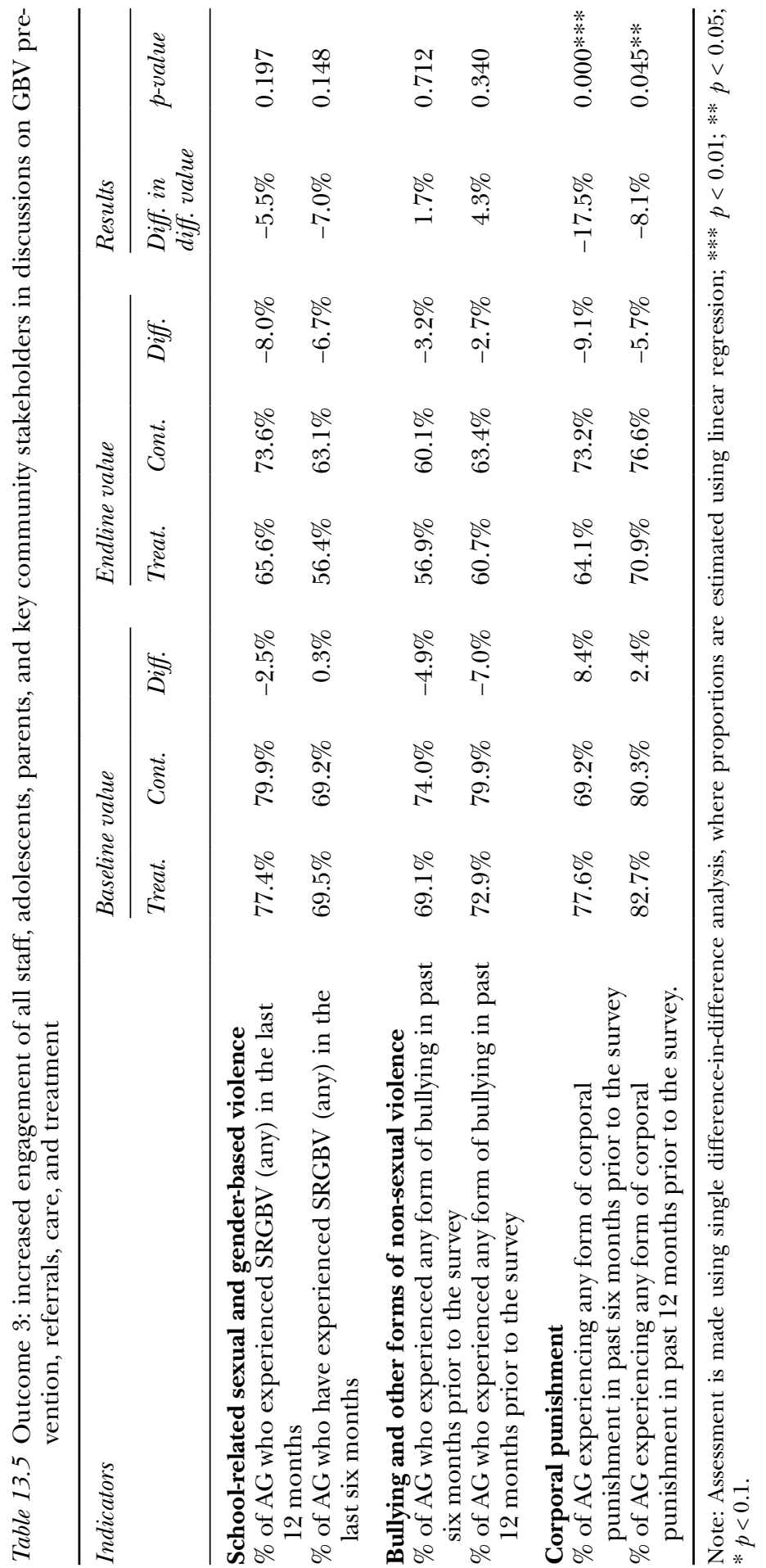


project scope. To address this, the authors further contextualize these findings in later sections of this chapter.

\section{Household/community-based survey of caregivers}

In each intervention district, a random sample of two villages was selected. In each selected village, 21 eligible households were sampled through village segmentation. An eligible household was one with at least one in-school AG aged 15-19; only one adult was interviewed in each household. A simple random sample of four villages was also taken in the control districts. In each selected village, 21 eligible households were sampled through village segmentation. The procedure for selecting school-based AGs and community-based caregivers in each of the districts is summarized in Tables 13.1 and 13.2.

In total, 672 completed surveys of parents or caregivers were obtained from the control and intervention areas. This demonstrates a $100 \%$ interview completion rate at baseline and endline. Interviews and surveys occurred in schools and communities for both AGs and caregivers, respectively. When an adolescent or caregiver could not be contacted, a replacement was allocated to achieve the required sample size. The figure represents an interview completion rate of $98.5 \%$; this achievement is adequate to provide findings from the selected schools.

\section{Key findings of the pre and post surveys}

Table 13.3 indicates that while there were slight improvements across indicators at endline, the intervention showed no significant effects. This is probably due to the limited length of the intervention. Two indicators that showed notable change are AGs who felt safe and protected while traveling to school (4.5\% increase) and AGs who felt safe and protected in their communities $(1.6 \%$ decrease). This seems to demonstrate that school efforts to increase safety were effective, while community interventions were not. This may also demonstrate increased AG awareness of safety issues in their communities as a result of the project's sensitization efforts.

Indicators around HIV prevention and transmission in Table 13.4 show no significant impact $(p<0.05)$. This could be because school retention was the focus, and not enough emphasis was placed on HIV knowledge. However, we see a significant positive effect in the number of AG who took an HIV test (10.8\% increase), which is known to be a protective factor against HIV infection. Similarly, we see a significant positive change in AGs who had sexual intercourse and age of sexual debut (with a reduction of $7.2 \%$ ever having sex and $9.5 \%$ fewer having sex before the age of 15).

Indicators for outcome 3 in Table 13.5 show significant impact. AG who experienced school-related gender-based violence (SRGBV) significantly decreased at 6 and 12 months by $7 \%$ and $5.5 \%$, respectively $(p<0.05)$. 
Table 13.6 Outcome 4: Gender norms and school participation

\begin{tabular}{|c|c|c|c|c|c|c|c|c|}
\hline \multirow[t]{2}{*}{ Indicators } & \multicolumn{3}{|c|}{ Baseline value } & \multicolumn{3}{|c|}{ Endline value } & \multicolumn{2}{|l|}{ Results } \\
\hline & Treat. & Cont. & Diff. & Treat. & Cont. & Diff. & $\begin{array}{l}\text { Diff. in diff. } \\
\% \text { value }\end{array}$ & p-value \\
\hline \multicolumn{9}{|c|}{ Gender norms and school participation } \\
\hline $\begin{array}{l}\% \text { of AG who } \\
\text { disagree with } \\
\text { at least three } \\
\text { harmful } \\
\text { norms and } \\
\text { attitudes that } \\
\text { violate the } \\
\text { rights of AG }\end{array}$ & $46.2 \%$ & $50.0 \%$ & $-3.8 \%$ & $38.6 \%$ & $49.6 \%$ & $-11.0 \%$ & $-7.2 \%$ & 0.161 \\
\hline
\end{tabular}

Note: Assessment is made using single difference-in-difference analysis, where proportions are estimated using linear regression; *** $p<0.01 ; * * p<0.05 ; * p<0.1$.

This demonstrates a correlation between the length of the project and the reduction of SRGBV experienced by AG. Similarly, bullying decreased by $4.3 \%$. Perhaps most significantly, rates of corporal punishment decreased at 6 and 12 months by $17.5 \%$ and $8.1 \%$, respectively, the gains increasing during the project's presence in schools.

Table 13.6 shows a decrease of $7.2 \%$ of AGs who disagree with at least three harmful norms and attitudes that violate their rights. This suggests that the normative change interventions attempting to influence attitudes about AG education were successful.

\section{Contextualizing project outcomes}

While the externally commissioned study yields important information about the overall project outcomes, SAGE coordinators also collected two other sources of data to contextualize these results. First, SAGE conducted sustained and systematic monitoring data, tracking participants in all intervention schools. SAGE produced monitoring data that corroborated results from the study (higher improvements in school retention at the end of the project). Of the 44,351 AGs supported by the project, $99.7 \%$ were retained in school. Of those, 2352 were flagged for SISC action and 95\% remained in school after additional support came from SISC members, PEs, and school administration. Through SAGE, 339 girls (14\% of those flagged at risk) who had already dropped out or were in the process of leaving received home visits to their parents/caregivers by adult members of a SISC. Of these atrisk girls, only 132 (5.6\% of those flagged at risk) dropped out, and 17 of them (13\% of dropouts) returned to school. In addition, 31,730 AGs have been mentored by community role models, 5285 have received life-skills training, and 8433 have learned how to make reusable sanitary pads. Also, 
23,539 have received HIV testing services through the project, and 509 have been extensively trained and empowered to serve as PEs on the SISC.

Second, SAGE coordinators engaged in longitudinal and sustained qualitative data gathering.

Qualitative methods were employed to collect data from different stakeholders, including focus group discussions (FGD) and key informant interviews (KII). Participants were chosen from ten selected schools and surrounding communities in five intervention districts (Lira, Oyam, Mukono, Mubende, \& Mityana) using convenience sampling. Respondent confidentiality was protected by masking traits of individuals or groups that could make them identifiable. A total of 13 KIIs were conducted with teachers, parents, government officials, school administrators, and other key informants using a structured interview guide. Then, 12 FGDs were conducted using a FGD checklist with 6-13 AG or parents in each group. A total of 81 adolescent girls 13-19 years old enrolled in secondary school and 48 parents/caregivers of AG (23 female; 25 male) participated in these FGDs.

These methods were deemed appropriate for collecting both in-depth and community information on knowledge, attitudes, and practices in addition to expert knowledge on the subject matter under assessment: HIV infections among adolescents and secondary school girl child dropout. The qualitative data was used to contextualize the quantitative findings from World Vision's university research partner. The information was also used to explore whether other sociocultural attributes influenced secondary school dropout rates for girls. Responses from the transcribed notes of the interviewer/moderator were assigned codes and labels that were used during data analysis. All data collected were analyzed based on content and selected topics as stated in the terms of reference. This provided the content and thematic analysis for the study (World Vision, 2019). While not the focus of the chapter, these qualitative data raised important insights about the project that were not considered in the externally conducted study.

\section{Challenges}

Notable challenges faced during implementation were the lack of conditional cash transfers for school fees, high levels of GBV in the community and schools, and exclusion of boys as direct beneficiaries. These challenges were difficult to overcome due to the project's short length of time for the intervention, as building stakeholder buy-in, piloting, and scaling a project in 151 schools, and being able to work with the AGs only while school was in session did not allow enough time for significant social norms change. Once implementation began, it became clear that many AGs dropped out of school because they lacked financial resources for school fees. This remained a challenge throughout the intervention. While the project team expected GBV to be an issue, the baseline results showed that more than 
$70 \%$ of AGs had experienced SRGBV, which called for a major course correction in programming. Financial and other resources were diverted to extensive GBV-reduction training for teachers, school administrators, and community dialogues. Efforts to shift perceptions on violence against children was one of the biggest challenges that SAGE faced. SAGE enforced policies by training teachers on the risks of corporal punishment and the benefits of using positive discipline in the classroom. This showed notable incremental positive change in social norms around corporal punishment and violence against children (e.g. a decrease of $17.5 \%$ in corporal punishment over 2.5 years). This incremental shift encouraged other project approaches, such as the AG-led EWS and peer-to-peer support structures, that enabled PEs to advocate for at-risk girls and for the SISC to act to retain them in school.

More broadly, there remains a disconnect between policy and practice concerning use of school attendance rosters. Most SAGE schools had not regularly taken roll in the classrooms even though government guidelines include this mandate. Teachers often do not understand the economic and social drivers or implications of school dropout, particularly for girls. Similarly, although gender equality is championed at the national level, it is not prioritized in homes and communities in much of Uganda. For example, the SAGE baseline study showed that only $54 \%$ of AGs strongly agree with the statement, "Girls and boys have equal opportunity to go to school", and only $56 \%$ of parents and caregivers strongly agreed with the statement, "In our community, we believe girls should be educated as much as boys".

Finally, in Uganda, it is uncommon to directly engage adolescents in the implementation of projects. The SAGE project worked within traditional family, gender, and leadership norms to sensitize participating schools and communities on the importance of AG leadership of the project. For instance, maintaining a six-girl majority in the SISC where AGs were decision-makers and equal contributors in a group of adults was unconventional yet instrumental in reaching the target population with the project interventions.

\section{Recommendations and future approaches}

Four key recommendations drawn from the projects are (1) school-based projects addressing dropout should include conditional cash transfers for AGs who lack resources for school fees, (2) social and behavioral interventions for AGs should include both interventions for violence reduction and HIV prevention, (3) these social and behavioral approaches should engage AGs and adolescent boys simultaneously, and (4) ample time should be allotted in projects working to change negative social norms around violence, education, and health. Qualitative data showed that most AGs in the project who were at risk of dropping out, or did drop out, were facing an inability to pay for school fees or basic scholastic requirements (World 
Vision, 2019). Dropping out meant they had a higher likelihood of engaging in risky sexual behaviors, including relationships with older men who were more likely to transmit HIV (World Vision, 2019; Pettifor et al., 2013). Girls cited lack of school fees as the catalyst that forced them into high-risk situations like sexually exploitative acts, brewing local alcohol, or early marriages. The exclusion of boys and young men from activities is a concern that should be addressed with urgency. This issue is especially salient in contexts where GBV and sexual and reproductive health are strongly associated with HIV prevalence in AGs. Our findings show that boys can be supported to be advocates against perpetrators of violence; boys can also protect themselves from HIV and AIDS, which in turn protects their sexual partners.

At a systems level, engaging with national and local government leaders is recommended to address the gap between national dialogue, policies, and practice. SAGE spent considerable time building awareness of the project among national and district government officials and engaging staff at health clinics and stakeholders in communities and schools. Without these important relationships in place, implementation would have been less effective.

We recommend that adolescents are kept at the core of programmatic strategies. AGs were consulted at each stage of design and implementation and seen as thought leaders. SAGE sought to give PEs an opportunity to grow through life-skills programming, including leadership, communication, sexual and reproductive health, HIV prevention and treatment, and menstrual hygiene management training. In turn, AGs led other aspects of the project, such as mentorship, designing health messages for their peers, and conducting trainings for fellow students. Adolescents must be empowered to take a central role in their health, trust healthcare providers, feel a sense of confidentiality, and be able to access services at convenient times. Although health clinics were engaged and sensitized to serve adolescents, there was not an adequate comprehensive support network, and a gap remains with referrals. Schools should collaborate with health facilities to provide spaces for adolescents to receive relevant health information, responses to their questions, and links to health services. Promisingly, AGs have embraced HIV testing services (HTS) and most now know their status (see Table 13.4).

Further research should seek to better understand why girls drop out of school. Teachers reported that out of 501 AGs who dropped out, 36\% (132) had been flagged by the EWS as being at risk. Of those who were not flagged, teachers reported that $24 \%$ dropped out due to lack of school fees, $18 \%$ dropped out due to pregnancy, $10 \%$ changed schools, and $6 \%$ got married. AGs who dropped out and who were not flagged by the EWS dropped out for reasons that in-school tracking of ABC predictors may not catch, such as school fees, pregnancy, and changing schools.

SAGE demonstrated the feasibility of implementing a social and behavioral approach to adolescent health promotion that employs a multi-sectoral 
and combination approach. School-based interventions are recommended because young people do not often visit health clinics and are generally assumed to be healthy (WHO, 2010). These interventions also have the potential to reduce stigma by normalizing HIV testing and counseling and creating an environment where adolescents can support one another to be tested, adhere to medication, and feel connected to their peers. There is great potential in programming that cross-cuts education, gender, and health sectors.

\section{Conclusion}

The adolescent-led EWS is a potentially effective tool to identify AGs at risk of dropping out of school and may be successful when scaled up elsewhere (including in primary schools) to reduce HIV-related vulnerabilities. In the three total sets of data (externally conducted survey, monitoring data, and qualitative), the project recommends there is much to be optimistic about with the EWS package.

The project monitoring and qualitative data suggests that the EWS package can effectively predict school dropout. The retention rate for the AG beneficiaries in the 151 schools was $99.7 \%$, compared with a national rate of $<70 \%$ for girls. This is a remarkable achievement, given that the project did not rely on cash transfers but rather on a combination approach of socio-behavioral interventions bridging the school, home, and community environments of AGs and supporting them to stay in school. The project monitoring and qualitative data indicates that the SAGE model is also highly effective at returning girls to school. Nearly all the girls $(95 \%)$ identified by the EWS as being at high risk of dropping out were retained in school, including the 17 girls who had already dropped out and returned to school following the SISC intervention. Monitoring data and qualitative results also implied that tracking all three $\mathrm{ABC}$ predictors is important to flag all at-risk AGs in different school contexts. While coursework performance had the highest individual predictive value of the ABC predictors $(75.4 \%), 37 \%$ of cases were identified by two or three indicators, which suggested that all three have value. The qualitative data suggests that $\mathrm{ABC}$ predictors alone are not enough but must be used with a combination package of socio-behavioral approaches for schools and communities to reduce dropout.

Given the complexity of the EWS package, it is important to consider which of the components have the highest prevention value. Increased confidence and empowerment of AGs played a central role in the EWS. Further research should examine programming that increases the number of AGs trained. Positive discipline training encouraged teachers to refrain from corporal punishment. In schools where this was strongly adopted, the qualitative data showed improved teacher-student relationships. Further assessment should look at whether student performance and attendance 
increased in classrooms where teachers practiced positive discipline. Finally, qualitative data showed that the model was more successful in schools where the head teacher and focal teacher were supportive and engaged and fulfilled their project-specific roles.

The SAGE model appears to be sustainable. Activities were built on already existing resources (people who advocate for girl child education, ministry activities, existing school programs, etc.). Qualitative data indicated that the transition of the EWS implementation to government and school officials should be completed on a school-by-school basis. This will help plan for low-cost continuation of activities, such as linking schools with manufacturers of reusable menstrual pad materials, redesigning the EWS register so it is more affordable to produce, and encouraging the Ministry of Health to include school HTS in their budgets. The SAGE model can be replicated in other contexts outside Uganda. We recommend additional implementation studies in other contexts.

\section{Note}

1 World Vision is a Christian humanitarian organization dedicated to working with children, families, and their communities worldwide to reach their full potential by tackling the causes of poverty and injustice.

\section{References}

Bronfenbrenner, U. (1979). The ecology of human development. Cambridge, MA: Harvard University Press.

Bruce, M., Bridgeland, J. M., Fox, J.H., and Balfanz, R. (2011). On track for success: The use of early warning indicator and intervention systems to build a grad nation. Baltimore, MD: Johns Hopkins University, School of Education, Everyone Graduates Center. Available at: http:/ /eric.ed.gov/?id=ED526421.

Coates, T.J., Richter, L., and Caceres, C. (2008). Behavioural strategies to reduce HIV transmission: How to make them work better. Lancet, 372(9639), 669-684. doi:10.1016/S0140-6736(08)60886-7.

Creative Associates International, and Mathematica Policy Research. (2015). Findings from the four country school dropout prevention pilot program impact evaluation. Available at: http://schooldropoutprevention.com/wp-content/uploads/2016/03/ Summary_Findings_Report_English_FINAL.pdf [Accessed 21 July 2019].

Fred Jones Tools for Teaching. Overview. Available at: www.fredjones.com/overview [Accessed 7 July 2019].

Govender, K., Masebo, W., Nyamaruze, P., Cowden, R. G., Schunter, B. T., and Bains, A. (2018). HIV prevention in adolescents and young people in the eastern and southern African region: A review of key challenges impeding actions for an effective response. The Open AIDS Journal, 12, 53-67. doi:10.2174/18746136018120 10053. Available at: https://www.ncbi.nlm.nih.gov/pmc/articles/PMC6062910/

Harrison, A., Newell, M. L., Imrie, J., and Hoddinott, G. (2010). HIV prevention for South African youth: Which interventions work? A systematic review of current evidence. BMC Public Health, 10, 102. doi:10.1186/1471-2458-10-102. 


\section{Julie DeSoto et al.}

Heppen, J.B., and Bowles Therriault, S. (2008). Developing early warning systems. Washington, DC: National High School Center, American Research Institutes.

Ministry of Education and Sports Uganda, and Education Information Management System. (2014). Education and sports sector fact sheet 2002-2015. Available at: http://education.go.ug/data/dcat/2/Data-and-Statistics.html [Accessed 20 April 2018].

Neild, R. C., Balfanz, R., and Herzog, L. (2007). An early warning system. Educational Leadership, 65, 28-33.

Pettifor, A., Bekker, L.G., Hosek, S., DiClemente, R., Rosenberg, M., Bull, S.S., Allison, S., Delany-Moretlwe, S., Kapogiannis, B.G., and Cowan, F. (2013). Preventing HIV among young People: Research priorities for the future. Journal of Acquired Immune Deficiency Syndromes, 63(2), S155-S160. doi:10.1097/ QAI.0b013e31829871fb.

Pettifor, A., Stoner, M., Pike, C., and Bekker, L. G. (2018). Adolescent lives matter: Preventing HIV in adolescents. Current Opinion in HIV and AIDS, 13(3), 265-273. doi:10.1097/COH.0000000000000453. Available at: https://www.ncbi.nlm.nih. gov/pmc/articles/PMC5902132/

Sawyer, S., Afifi, R.A., Bearinger, L.H., Blakemore, S.J., Dick, B., Ezeh, A.C., and Patton, G.C. (2012). Adolescence: A foundation for future health. Lancet, 379(9826), 1630-1640. doi:10.1016/S0140-6736(12)60072-5.

Stoner, M. C. D., Pettifor, A., Edwards, J. K., Aiello, A. E., Halpern, C. T., Julien, A., Selin, A., Twine, R., Hughes, J.P., Wang, J., Agyei, Y., Gomez-Olive, F. X., Wagner, R. G., Macphail, C., and Kahn, K. (2017). The effect of school attendance and school dropout on incident HIV and HSV-2 among young women in rural South Africa enrolled in HPTN 068. AIDS (London, England), 31(15), 2127-2134. doi: $10.1097 /$ qad.0000000000001584.

USAID. (2019). Positive youth development (PYD) framework. Available at: www.youth power.org/positive-youth-development-pyd-framework [Accessed 2 July 2019].

World Health Organization. (2010). Social determinants of health and well-being among young people: Health behaviour in school-aged children (HBSC) study. Available at: www.euro.who.int/_data/assets/pdf_file/0003/163857/Social-determinants-ofhealth-and-well-being-among-young-people.pdf [Accessed 20 April 2018].

World Vision. (2019). DREAMS: Determined, resilient, empowered, AIDS-free, mentored and safe women. Available at www.worldvision.org/dreams [Accessed 7 July 2019]. 